\title{
US halts search for extra-terrestrial intelligence
}

A US congressional subcommittee has severely cui back a request from the National Aeronautics and Space Administration for funds to begin a search for extra-terrestrial intelligence, thus according to NASA officials effectively 'killing' the project.

The subcommittee has also denied the agency's request for funds that would allow the Space Shuttle to prevent the descent and disintegration of Skylab, on the grounds that current delays in the Shuttle development programme put the success of such a mission in doubt. And as a further consequence of the shuttle delays, the subcommittee has directed NASA to set up a 'contingency fund' of $\$ 30$ million to cover any extra costs that the shuttle programme may incur. This money would be taken from the funds for three major space science projects which have already been requested for the fiscal year 1979: the Solar-Polar Orbiter Mission (cut back by $\$ 5$ million), the Large Space Telescope (cut by $\$ 15$ million), and the Jupiter Orbiter Prohe.

Scientists regard the most critical of these as being the possible cut in the budget for the Solar-Polar Orbiter Mission. A one-year delay in funding could mean a three year delay in the project until the Earth, and Jupiter (whose gravitational pull is necessary to send the spacecraft over the poles of the Sun) are once again in a favourable position relative to one another.

The effect of these cuts, if they are left standing when the NASA budget request is discussed by the full House, could be to set back significantly each project (although delays in the Shuttle programme would inevitably

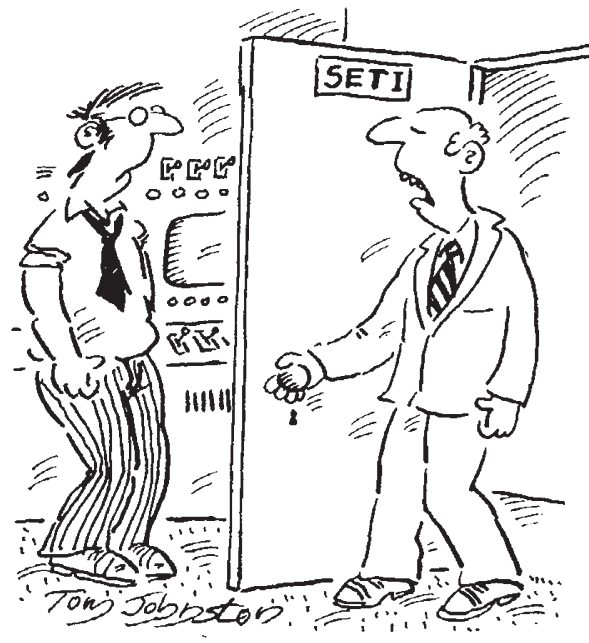

"Close down encounters of the third kind" result in delays in launching the Space Telescope, which is to be one of the Shuttle payloads).

The budgetary decision was made by a subcommittee of the House Committee on Appropriations under the chairmanship of representative Edward P. Boland. Last year the same subcommittee recommended that funds be witheld for a start to the Jupiter Orbiter Probe in 1978, a decision only overturned on the floor of the House after an intense lobbying effort by the space science community.

The subcommittec has recommended that the budget for the search for extra-terrestrial intelligence (SETI project) be reduced to $\$ 600,000$ from a requested $\$ 2$ million. "This is not enough even to start design work on the antennae," a NASA official said last week.

As regards the cut in NASA's request for funds to boost Skylab back into an orbital path, the subcommittec has said that it would be prepared to consider an additional request for funds to do this if current attempts to reactivate Sklyab's engines, and thus keep it in orbit until Space Shuttle is ready, are successful.

David Dickson

\section{Copernicus Astronomical Center opens in Warsaw}

THe OfFICIAL opening, on 24 May 1978, of the Copernicus Astronomical Center in Warsaw marks the beginning of a new era of collaboration between theoretical astronomers from eastern and western countries. The institute promises to be an important meeting place, especially as Soviet astronomers are likely to find it easier to get to Warsaw than say Cambridge or Princeton. Furthermore it adds recognition to the outstanding advances made by Polish astronomers in the understanding of binary stars.

In 1970 Józef Smak, the present director, and Bohdan Paczynski set out proposals for an international centre that could be constructed at relatively low cost. They envisaged that such an institute could help Polish researchers keep in touch with one another, as well as providing good facilities for visitors from other countries.

At the outset there seemed to be no chance of getting the necessary finance. However, when Paczynski aired his ideas in the USA, colleagues suggested an approach to the National Science Foundation (NSF). This led the Polish Academy of Sciences to make a formal proposal to the NSF. The aims of the project were evidently well received. Academy of Sciences to make a formal In 1973, the five hundredth anniversary of the birth of Copernicus, the NSF presented the equivalent of $£ 1,4$ million in Polish currency to enable a new institute to be founded for Polish astronomers.

The center includes a hotel capable of accommodating a dozen visitors and their families. This hotel will be valuable since the language and cultural difficulties that most scientists would otherwise experience are largely removed. An adequate budget will provide for the living expenses of western visitors; this is essential as the official exchange rate is unfavourable for long-term visitors.

Currently the office facilities are spacious but they will become rather cramped if a proposal to base a space research group there is carried out. A PDP 11/4S computer, purchased with a donation of $\$ 100,000$ is available for modelling stars and galaxies.

For many years the Warsaw school of astronomers has been at the forefront of thinking on the properties of close double stars. Another important research area is that of stellar evolution, cspecially the study of instabilities, variations, and the effect of (hypothetical) highly-condensed cores on the evolutionary behaviour. A new ficld under development is that of highenergy astrophysics, particularly in the relativistic regime.

To improve contact between the fragmented schools of astronomy in Poland, the Copernicus Center will have a vigorous program of workshops, think-tanks, and graduate study program. It will also act as the main center for stellar evolution studies in eastern Europe.

What will be of special significance to visitors from the UK and USA is the possibility of collaborating with Soviet astronomers who normally find it very difficult to get permission to visit the west for extended periods. Polish astronomers have already made cxcellent contacts with researchers in other countries. Now they are in a good position to return hospitality and make further important contributions on an international basis.

Simon Mitton 